Please send trade news information and illustrations to Arveen Bajaj at the $B D J$, Nature Publishing Group, The Macmillan Building, 4-6 Crinan Street, London N1 9XW.

Trade news is provided as a service to readers using text and images from the manufacturer, supplier or distributor and does not imply endorsement by the $B D J$. Normal and prudent research should be exercised before purchase or use of any product mentioned.

\section{CARES - custom implant abutments}

Straumann and Sirona have joined forces to bring you Straumann CARES offering exclusively customised implant prosthetics for the Straumann Dental Implant System. The CARES service uses the customised synOcta prosthetic components with a Regular Neck shoulder (RN Ø 4.8 $\mathrm{mm})$. Care custom abutments can be manufactured in zirconium oxide or titanium oxide. The ceramic custom abutment is fixed to the synOcta 1.5 abutment. RN synOcta custom abutment and the titanium custom abutment is screwed directly into the implant.

The dental laboratory records the implant position from the model and designs the abutment shape. The custom abutment is fabricated at the Straumann production centre on the basis of the design data transmitted via the Internet. In just a few working days after an order is placed, the end product and the corresponding screw, manufactured according to the high standards of precision and quality from the Straumann Dental Implant System, are sent to the customer by courier. The custom abutments enable cement-retained single-tooth superstructures to be produced on Straumann Regular Neck implants in both the anterior and posterior regions.

Reader response number 51

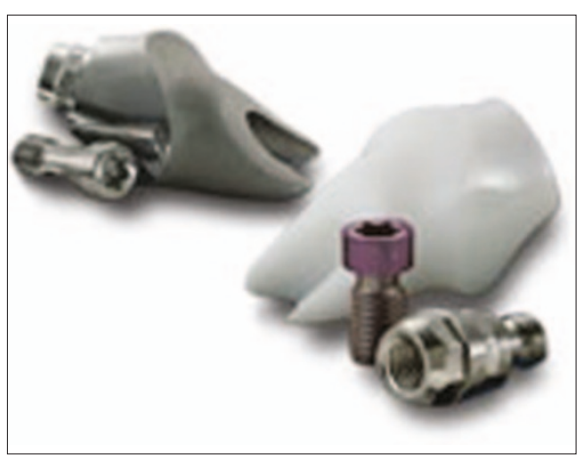

\section{One step composite polishing}

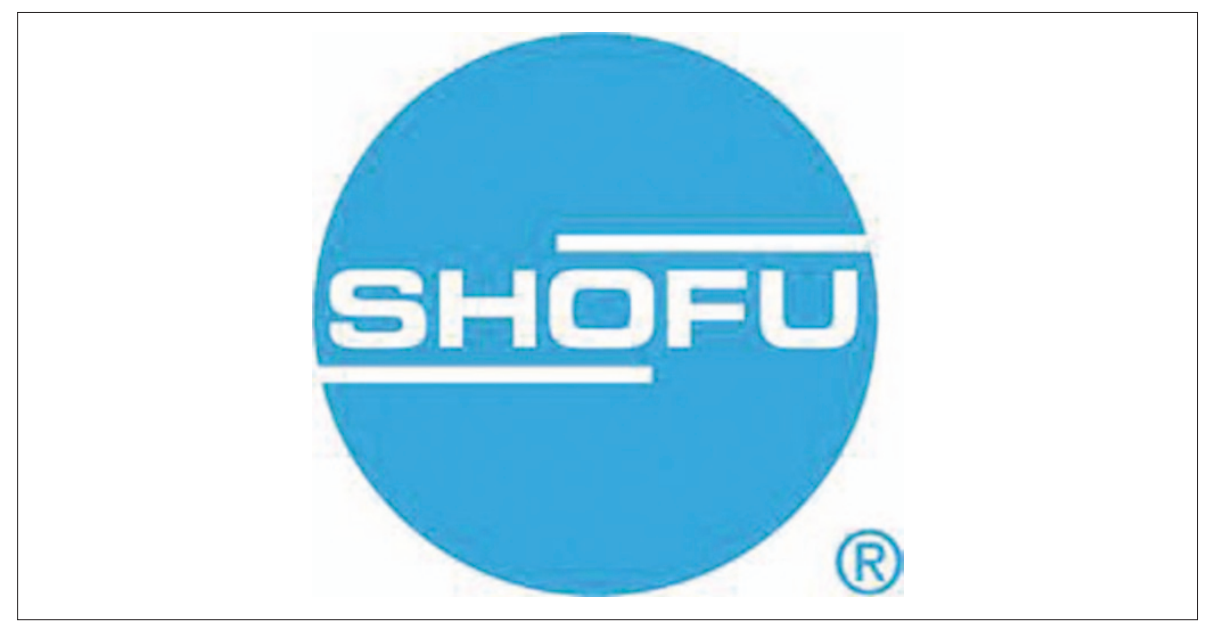

For over half a century, Shofu have been developing and producing abrasives and polishers. The latest addition includes One Gloss. This unique one-step finisher and polisher can be used to finish and polish all composites restorations simply by altering the contact pressure on the restoration, without having to change instrument. One Gloss can also be used for the removal of stains or excess resin cement from tooth surfaces without damaging the enamel, which has proved to be particularly useful in orthodontic cases and polishing after scaling, thus reducing chair-side time. One Gloss is packaged in a set of 60 polishers (20 each of Cup, Midi Point and Inverted Cone shapes) and 3 x CA Mandrels plus instructions. For further information please contact Shofu on 01892870800. Reader response number 50

\section{Prestige Dental online... Enter a competition to win free flights...}

Many clinicians associate Prestige Dental with just a couple of well known branded products such as Denar or Cendres Metaux. However, the complete portfolio also includes many varied and interesting products from manufacturers such as Dux Dental, Parkell Inc, Pulpdent, NTI and more. These products can now be viewed along with courses, up-to-date news, promotional offers and archives of the popular 'Prestige Practicalities' literature, which features clinical hints and tips for everyday practice. Simply visit www.prestige-dental.co.uk to enter an interesting dental website. Upon visiting the site you will also be able to request copies of the 'Prestige Practicalities' and enter the special prize draw that is open to all visitors until 31 March 2006. The prize is two free return flights from the UK to any European destination of your choice. To enter you will need to visit the Prestige Dental website and leave your email address, which will also enable you to receive up to date information on courses and product news. The winner will be drawn on 3 April 2006 and announced to all entries.

Reader response number 52 
.

\section{Liquid mouth rinse}

Pegasus Dental, part of the Astek Group, are pleased to announce the launch of their new lower cost and super concentrated mouth rinse which takes the place of traditional mouthwash tablets. A fresh minty taste with instant dissolving provides the perfect answer for busy dentists, nurses and hygienists who want to offer their patients a modern sugar and alcohol free alternative. The new Pegasus Liquid Mouth Rinse comes in a super concentrate $90 \mathrm{ml}$ bottle, making up to 1,100 chair-side rinses, which apart from the usual post-op use additionally makes for a wonderful fresh bouquet to mask bad odours with patients who may unfortunately suffer with bad breath. Each $90 \mathrm{ml}$ bottle of Liquid Mouth Rinse is priced at $£ 9.95$ plus VAT and is available from your usual retail supplier or you can contact Astek Innovations directly on tel: 01619423900 fax: 01619423901 email: info@astekinnovations.co.uk. The entire Pegasus range may be viewed on www.astekinnovations.co.uk.

Reader response number 55

\section{Denti-Brush:}

\section{wire-free interdental brushes}

Denti-Brush interdental brushes are uniquely designed for a more effective approach to cleaning between the teeth. They are wire-free helping to eliminate gingival trauma. The rubber tips are coated with sodium fluoride with obvious oral health benefits and the pack of assorted sizes adapt to different interdental

spaces. For further
information please
contact Periproducts
Ltd, tel 020 8868
1500 or email denti-
brush @ periprod-
ucts.co.uk.
Reader response
number 56

\section{Dental Sky's oral healthcare solutions}

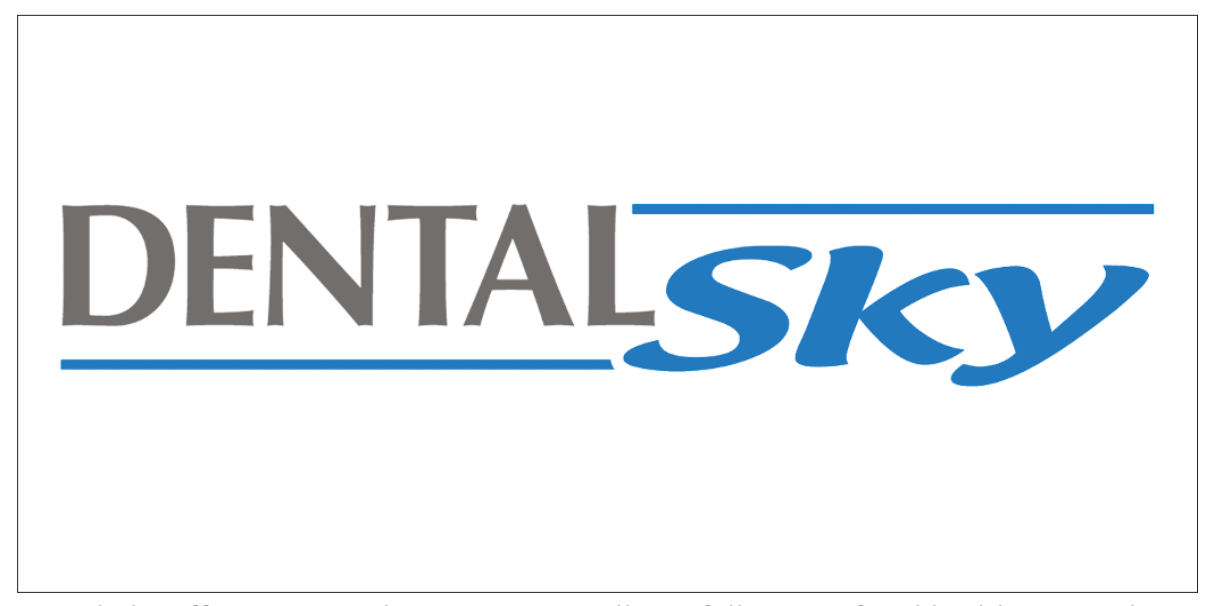

Dental Sky offers an exemplary service as well as a full range of oral healthcare products, all at extremely competitive prices. The team at Dental Sky is trained to volunteer skilful advice on, for example, the huge range of toothbrushes currently available. So whether you are looking for a branded product or the less expensive alternative of Dental Sky's own label products the team will guide you to help you make the right decision at the right price. Dental Sky's 'Biotene' products offer you great value for money. Biotene mouthwash is 100\% alcohol-free and contains three antibacterial enzymes that kill bacteria found in common oral infections and gingivitis. Soothing as it cleans, Biotene Mouthwash quickly helps to neutralise mouth odours without masking them. Conveniently packaged with a handy flip top lid, Biotene Mouthwash protects without staining and is priced at $£ 6.80$ for a $250 \mathrm{ml}$ bottle. For more information, call Dental Sky on 08002944700. Reader response number 53

\section{Oral health at Molar Ltd}

Molar Ltd is the exclusive distributor of quality oral hygiene products designed to help patients maintain optimum oral hygiene at home. The range currently includes TePe, BioXtra, ProDen PlaqueOff, TongueDetox and QuitStics. In the UK, TePe is best known for their Interdental brushes which are the most recommended and used amongst hygienists and dentists. TePe also provide other products, including manual toothbrushes, specialist brushes (Interspace, Compact Tuft, Proximal, Implant/ortho) as well as other Interdental devices such as the Miniflossers, plastic and wooden dental sticks and Tape. BioXtra is a range of products for sufferers of xerostomia.

The range contains specially formulated toothpaste, gel, mouth rinse, spray gel and chewing gum which can help alleviate dry mouth conditions and help maintain oral hygiene. ProDen PlaqueOff offers a new and easy solution for those patients who have difficulty in controlling plaque and calculus using traditional methods. This natural food supplement is patented to work systemically to reduce plaque and calculus. The Molar range of products are available from all dental wholesalers. For further information or to order please call 01934 710022 or email info@MolarLtd.co.uk. Reader response number 54

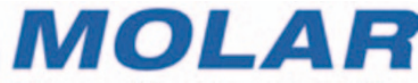

The oral hygiene supplier 


\section{Oral-B Triumph}

The Oral-B Triumph is a toothbrush that communicates with the user. It has a microchip in the handle to help the user brush more effectively. There are prompts when it's time to change a brush head and the unit is smart enough to know which head is used, and will chose the appropriate cleaning mode. A quad pacer will help ensure the user pays equal attention to all parts of the mouth. There is also a display to indicate the length of battery life remaining. The Oral-B Triumph has four different brushing modes: 'clean', 'soft', 'massage' and 'polishing' and in order to derive maximum benefit from these different options, new brush heads were launched simultaneously. FlossAction brushheads contain a microchip that communicates with the handle so that it automatically operates in 'clean' mode.

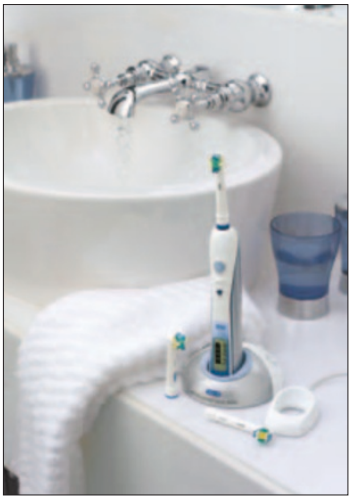

Triumph's second brush head option is a dentist inspired model called ProBright; this features a soft, prophylike cup in the centre of the bristle configuration and has been proven to provide cleaner, naturally whiter teeth in 21 days. This head also contains a chip, which alerts the handle to operate in 'polishing' mode. Both heads are also compatible with all other Oral-B ProfessionalCare and AdvancePower handles.

Reader response number 57

\section{ProSmile Handy}

Minerva Dental are distributors of the ProSmile Handy prophylactic handpiece from Sirona. It is used for minimally invasive and effective removal of plaque, soft accretion and discolouration on tooth surfaces, fissures and interdental spaces. It has an elegant, practical design that ensures easy operation and an ergonomically balanced contour that allows its operation without stress or fatigue. Its freely adjustable handpiece, with either $120^{\circ}$ or $90^{\circ}$ spray jets, ensures optimum access throughout the mouth. It is manufactured from high quality materials to ensure easy cleaning and sterilisation. It can be attached to most standard quick couplings for high-speed handpieces, saving time and money. The prophylactic powder is stored in a large capacity reservoir, which enables several patients to be treated without refilling. With highly impressive flow and removal properties, the spray is easily regulated. Powder refills and $120^{\circ}$ or $90^{\circ}$ spray jets are available separately. For further information please ask your local Minerva Representative or telephone 02920490504. Reader response number 58

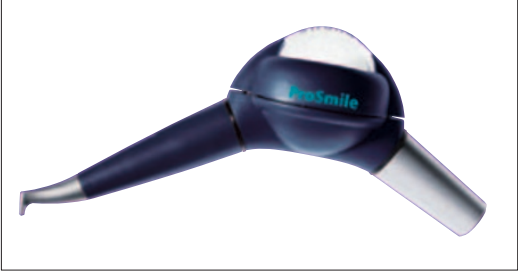

\section{Natural Dentist}

Oraldent have developed a range of products that maintains healthy oral environment using a combination of herbal extracts. Natural Dentist's products are all free of alcohol and sugar, meaning they are ideal for diabetics, pregnant women and children. The Natural Dentist range comes in a variety of flavours and formulations, and also offers a toothpaste which is free of sodium lauryl sulphate (SLS). SLS is a synthetic detergent commonly used in toothpaste, but studies suggest it may cause recurrent ulcers and other oral irritations in $20 \%$ of the population. Using SLS free toothpaste could reduce oral discomfort for many people who suffer with these conditions. A study conducted at the New York University College of Dentistry showed herbal toothpaste and gum therapy effectively reduced gingivitis, gingival bleeding, plaque and staining, and further studies proved the

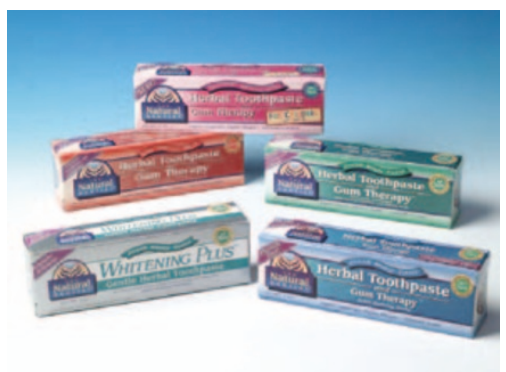
products to be a more potent weapon against bacteria than many leading brands. For more information about Oraldent's Natural Dentist SLS Free Toothpaste and the full range, please contact Oraldent on 01480862080.

\section{All-Ceramic Excellence}

One of the best ways to help maintain optimised oral health is by offering All-Ceramic Excellence as an alternative to conventional non-precious metal based restorations, with the soft tissue reactions they regularly cause including grey margins. This is why Techceram Technology Centre (TTC), Techceram's in-house dental laboratory are proud to announce that they've been appointed the second Lava Milling Centre for the UK. This means that TTC now produce an even wider choice of substructures for all-ceramic restorations including Techceram flame sprayed alumina ceramic bases for single unit restorations, and a choice between Lava and Cercon precision fitting milled Zirconia substructures for multiple unit restorations. All three offer the perfect balance of function, aesthetics and biocompatability. Being all-ceramic systems, they eliminate the aesthetic problems traditionally associated with non-precious metal based restorations and are more biocompatible with gingival tissue in the longer term. Techceram, Lava and Cercon are supplied with a five year guarantee, conditional on the clinician following the recommended clinical procedure and participating within their unique 'Quality Feedback Network'. Please contact Techceram Ltd on 01274416664 for further details.

Reader response number 60

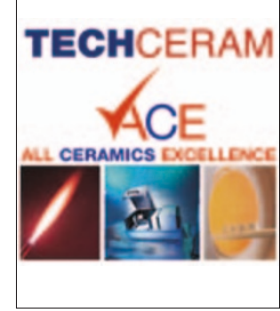

\section{Europe's market leading fluoride varnish}

Ivoclar Vivadent's Fluor Protector, Europe's market leading fluoride protector, is recommended by the WHO for its cost-effective solution to problem caries. Shielding against caries, it can even repair initial carious lesions. Its ability to adhere to tooth surfaces prolonging fluoride exposure and uptake. Compared with other fluoride varnishes it has a more pronounced fluoride uptake and retention even though it has a lower fluoride content. Fluor Protector is safe to use because potentially nephrotoxic plasma fluoride levels are never reached, unlike high fluoride containing gels. Therefore it can be safely used even on small children. Effective in the treatment of hypersensitive cervicals and longterm caries prophylaxis, Fluor Protector is an homogeneous solution containing $0.1 \%$ fluoride, it exhibits excellent tooth surface wetting and outstanding adhesion. Once applied it forms a protective calcium fluoride layer, which provides targeted care of risk areas over an extended period of time. Just two applications per year are normally sufficient. Supplied in single dose bottles or ampoules, Fluor Protector can be applied quickly and economically. For further details contact your local representative, visit www.ivoclarvivadent.com or telephone 01162847880.

Reader response number 62

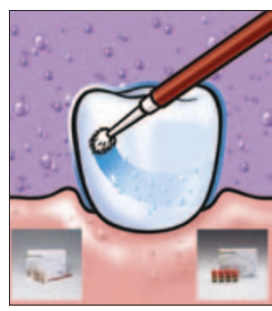

